\title{
GÊNERO, SEXUALIDADE E DIREITOS HUMANOS NA EDUCAÇÃO ESCOLAR: ENTRE IGUALDADES E DIVERSIDADES, A DIFERENÇA
}

Michele de Freitas Faria de Vasconcelos ${ }^{1}$ Jeane Félix ${ }^{2}$

\section{Resumo}

Esse texto objetiva discutir tensionamentos políticos e pedagógicos envolvidos no desdobrar do direito à educação como um direito à igualdade e à diferença; e pensar o desafio do se criar uma zona de habitação entre igualdade e diferença no campo das políticas públicas educacionais, tomando o gênero como um operador de análises. O movimento metodológico é o de tentar imprimir um olhar de problematização, posicionando-nos contra o esvaziamento de sentidos pela naturalização de noções tão utilizadas na luta política como a de direitos e a de humanidade. Nesses tempos em que alunos/as e professoras/es se perguntam o que estão fazendo ali, nos parece que a escola tem uma função fundamental de educar para a cidadania. Apostamos na potencialidade de se fazer (micro)política no ambiente educacional, exercitando coletivamente, por entre polifonia de vozes diversas, o direito à educação (e não só a escolar) como um direito de todos/as, de cada grupo e de cada um/a.

Palavras chave: Educação; Escola; Direitos Humanos; Gênero; Sexualidade

\section{O CONTEXTO}

Século XXI, era dos Estados Democráticos de Direitos. Nela, um campo de relações de poder funciona "no jogo complexo entre interesses individuais e coletivos, entre o

\footnotetext{
${ }^{1}$ Mestrado em Saúde Coletiva (ISC/UFBA); doutorado em Educação (UFRGS). Endereço: UFS Campus Universitário Professor Alberto Carvalho, Departamento de Educação/DEDI. Avenida Vereador Olímpio Grande, s/n, Centro. Itabaiana - Sergipe, Brasil. CEP: 49500000. Endereço eletrônico: michelevasconcelos@ @otmail.com

${ }^{2}$ Mestra (UFPB) e Doutora (UFRGS) em Educação. Endereço: UFS Campus Universitário Professor Alberto Carvalho, Departamento de Educação/DEDI. Avenida Vereador Olímpio Grande, s/n, Centro. Itabaiana Sergipe, Brasil. CEP: 49500 000. Endereço eletrônico: jeanefelix@ gmail.com
} 
VASCONCELOS, M. F. F.; FÉLIX, J.

equilíbrio do mercado e o regime do poder público, entre direitos fundamentais e independência dos governados" (FOUCAULT, 2008, p. 61). As práticas governamentais zelam, assim, para que a mecânica dos interesses não incorra em riscos e perigos nem para os indivíduos, nem para a população; havendo composição entre estratégias de seguridade, bem ao lado da fabricação de liberdades. Tempo de Direitos Humanos. Muitos e muitas empunham sua bandeira, símbolo compósito e signatário de inúmeras lutas deflagradas no século passado, por diferentes movimentos sociais e políticos. Afirmados ou negados, reconhecidos ou violados, eles atravessam nosso cotidiano, norteando nossas preocupações e buscas.

No Brasil, particularmente, no campo da Educação, os direitos humanos vêm ocupando, atualmente, um espaço de destaque nas mais diferentes arenas políticas. Nesse terreno, dá-se uma disputa por quais conhecimentos são válidos para serem ensinados nas escolas. Um exemplo atual dessa disputa, que se deu e se dá em nome dos direitos humanos, foi a retirada das questões de gênero e sexualidade do documento final do Plano Nacional de Educação 2014-2024 (BRASIL, 2014) após pressão das bancadas mais conservadoras do Congresso Nacional. Este texto almeja justamente refletir como gênero e sexualidade integram e compõem disputas em torno dos chamados Direitos Humanos, reflexão para nós indispensável quando o que se pretende é promover direitos humanos no âmbito da (ou de uma) educação. Mas que direitos estamos querendo promover? Para que humanos?

O movimento metódico de nosso texto é, pois, o de tentar imprimir um olhar de problematização para o cenário dos direitos humanos no âmbito das políticas públicas educacionais, posicionando-nos contra o esvaziamento de sentidos pela naturalização de algumas noções tão utilizadas na luta política como a de direitos e a de humanidade, uma humanidade generificada e sexualizada (ou se existe como homem ou como mulher; como hetero ou como homossexual, os primeiros termos guardando sempre uma relação 'superior' de hierarquia. Esses processos se dão, nessa perspectiva, sempre em uma relação dicotômica na qual devemos ser OU uma coisa OU outra, nunca as duas coisas ao mesmo tempo), diga-se de passagem. Almejamos, ao invés disso, datar sentidos, entendendo, com Coimbra, Lobo e Nascimento (2009) que o direito, o humano, o gênero, "são construções das práticas sociais em determinados momentos, que produzem continuamente esses objetos, subjetividades e saberes sobre eles" (p. 36) a partir "das experiências de cada um[a] de nós na coletividade, na imanência das nossas práticas e das lutas de nosso tempo histórico" (p. 39). Então, que direitos queremos exercer? Qual o rosto da humanidade no qual queremos apostar? 
Nesse nosso cenário de governamentalidade (neo)liberal, renova-se a importância de um intervencionismo judiciário: a lei dá aos indivíduos a possibilidade de se comportarem como querem e ao mesmo tempo regula danos provocados por irregularidades de comportamento. A lei funciona como um importante instrumento de codificação das relações.

Assim, os direitos e a cidadania parecem funcionar como um modo eficiente de promover a fácil condução dos seres humanos base na obediência. Em outros termos, trata-se de "um investimento na inibição de resistências pela cidadania, pela convocação à participação democrática, religião moderna do rebanho, um direito por deveres em nome de todos os homens [e mulheres] livres" (PASSETTI, 2003, p. 27). Do mesmo modo, convocadas pelo objetivo de governo das condutas, práticas educacionais muitas vezes parecem acoplar-se a um 'cuidado' estatal-policialesco e movimentos de 'resistência' a restringir-se a reivindicações e exigências feitas pela população por um mais Estado social, ou seja, por uma maior intervenção estatal sobre suas vidas. Não nos esqueçamos de que, em tempos biopolíticos, a vida se torna o palco das lutas políticas e sociais:

Foi a vida, muito mais do que o direito, que se tornou o objeto das lutas políticas, ainda que essas últimas se formulem através de afirmações de direito. O "direito" à vida, ao corpo, à saúde, à felicidade, à satisfação das necessidades, o "direito", acima de todas as opressões ou "alienações", de encontrar o que se é e tudo que se pode ser, esse "direito" [...] foi a réplica política a todos esses novos procedimentos do poder. (FOUCAULT, 2001, p. 136).

Dito de outro modo, o controle sob a forma de lei - da garantia de direitos, bem como da aplicação de penalidades - fulgura nesse horizonte como a proteção necessária, a qual ninguém, em 'sã consciência', poderia abdicar, a qual, todos/as e cada um/a devem exigir. E, assim, assiste-se ao processo de judicialização da vida cotidiana e à produção de subjetividades paranoicas, punitivas, policialescas, armadas até o topo de identidades que lhes garantem o suplemento para uma vida controlada pelo Estado e pelo mercado.

Todos/as e cada um/a de nós, corpos organizados, corpos marcados pelo poder, corpos governados e governáveis, cidadãos/ãs responsáveis, devemos ao Estado e ao mercado. Primeiramente, devemos ser individualizados, identificados, organizados, únicos, sujeitados. Devemos ser grupos e comunidades delimitados, cujo reconhecimento também advém via luta por identidade. Identidades, mesmo as dissidentes, devem ser reconhecidas - e, desse modo, também advir soberanas - também os corpos 'resistentes' devem construir um 'rosto' 
homogêneo. Direitos e deveres: identidade, delimitação, depuração, controle. Devemos ser corpos individuais e sociais que marcham com o Estado e o mercado.

O Homem, o homem da razão, possuidor de uma identidade indivisa e soberana, masculino, branco, adulto, heterossexual, trabalhador, viril, 'encorpado', sadio, 'chefe' de família que tem um nome a zelar e dá esse nome à família, que foi conformado por meio de educação escolar, que tem bens e patrimônios a honrar e que honram esse nome, que tem poder de consumo, de endividamento, cartão de crédito, que tem casa, endereço fixo, tudo isso lhe concedendo um local de poder e de autoridade como sujeito universal: a Humanidade. Deleuze (1992) afirma que essa forma-Homem surge no século XIX e se reedita em contextos contemporâneos: "a forma do homem, a forma-homem, é uma moldagem histórica complexa e mutante" (PELBART, 2003, p. 32). A ela, tendemos a estar colados, a partir dela, nos subjetivamos. Fixação, identidade, forma, fôrma subjetiva...

Mas o que se opera, o que dá sustentação à forma-Homem quando da morte do deus trabalho e de seu modo de culto, a educação? E quando se suspeita de que, através do trabalho, da educação e da segurança, não se melhore a 'qualidade' de vida da população? E quando o sexo parece não ser mais o rei definidor maior da 'identidade humana'? E quando se proclama o direito a ser diferente e a tolerância à diversidade?

Nos dias atuais, assiste-se à modulação de tal forma-Homem, que se flexibiliza para absorver novas demandas e, justamente desse modo, parece manter sua força de captura. Nesse sentido, há a reedição de marcadores identitários e humanitários e, com ela, novos contornos são assumidos pela forma-Homem. Dois termos que compõem tal forma parecem importantes de ser aqui analisados, na medida em que funcionam como 'ideias justas', palavras de ordem, imagens-clichê que parecem ditar nossa percepção e governar nossas condutas (DELEUZE, 1992), quais sejam: identidade, diversidade/multiculturalismo.

Cenário de confinamento identitário, "quando as figuras estabelecidas são tomadas como identidades e seu abalo [...] interpretado como ameaça de desagregação, para manter-se no mesmo lugar, é-se capaz de fazer qualquer coisa, inclusive matar" (ROLNIK, 1998, p. 66), basta pensarmos no que se tem feito em nome de identidades nacionais, religiosas, étnicas e raciais, mas também sexuais, de gênero, de sexualidade, em nome, enfim, da segurança da população identificada como cidadã de bem.

Cenário também de proclamação da diversidade/multiculturalismo. Por meio da veiculação de uma aceitação da diversidade e da tolerância à diferença, parece se dar um governo dos 'diferentes' por meio da justaposição de conjuntos homogêneos. Dessa forma, as 
tão proclamadas políticas de inclusão, com suas retóricas de cidadania, democracia, aceitação, pluralidade, seguem com o objetivo de "refazer a Unidade ou, pelo menos, administrar a Diversidade, mesmo que seja, isso sim, a partir do ponto de vista da vantagem do Capital e da ordem do Estado" (LARROSA; SKLIAR, 2001, p. 10). No interior de tais políticas, ainda identitárias,

[...] teríamos de aceitar e celebrar as diferenças, porém, isso sim, representando-as, desativando-as, ordenando-as, fazendo-as produtivas, convertendo-as em problemas bem definidos ou em mercadorias bem rentáveis; teríamos de produzir e canalizar os fluxos e os intercâmbios, porém, isso sim, de forma ordenada, vigiada e produtiva: teríamos de convocar toda alteridade possível, de permitir-se todas as comunicações, porém, isso sim, silenciando, dosando, ressignificando e harmonizando as vozes dissonantes, governando os silêncios dilacerantes e regularizando e rentabilizando os deslocamentos.

Cabe indicar que as reflexões que aqui apresentamos foram produzidas a partir de nossas experiências na docência e na gestão de políticas públicas em âmbito nacional. A partir do olhar metodológico da problematização/desnaturalização das imagens-clichês produzidas nesse (nosso) contexto de governamentalidade biopolítica de face neoliberal, buscamos modos de reexistência (política). Nessa perspectiva, espreitamos por um exercício de direitos que borre a "cidadania da sujeição" (CARVALHO, 2009), inclusive a normas regulatórias de gênero, as quais requerem (auto)policiamento das condutas, por meio das quais se organizam os corpos colando-os a um rosto homogêneo e transcendental de homem e humanidade (acoplamento à forma-Homem). Em vez dessa cidadania da sujeição, ensaie-se uma cidadania que brota não de identidades soberanas, mas imanentes a processos singulares, num movimento associado a práticas cotidianas (CARVALHO, 2009; COIMBRA, 2001).

\section{O TEMA E O TEXTO}

Pontuado o contexto e nosso 'método' de abordagem, queremos situar nossa reflexão a partir da assertiva de Boaventura de Souza Santos (2003, p. 56): "Temos o direito a ser iguais sempre que a diferença nos inferioriza. Temos o direito a ser diferentes sempre que a igualdade nos descaracteriza”. Tal assertiva sintetiza desafios colocados para as lutas e estratégias de garantia de direitos humanos nos nossos tempos, as quais têm habitado uma zona paradoxal entre igualdade e diferença. Aqui entendemos paradoxo como uma ideia, um 
conceito que entrecruza o que, no bojo de nosso pensamento binarista, "deveria permanecer separado [...] de maneira que dois planos se confundem em um só e, no entanto, continuam diferenciáveis" (VARELA, 1981/1994 apud EIRADO e PASSOS, 2004, p.80).

Esse texto tem, assim, como objetivos: discutir alguns dos tensionamentos políticos e pedagógicos envolvidos no desdobrar do direito à educação como um direito à igualdade e à diferença de forma concomitante; e pensar o desafio do se criar uma zona de habitação entre igualdade e diferença no campo das políticas públicas de Educação, tomando o gênero como um operador de análises, na medida em que tais políticas tendem a ser tecidas de modo generificado (MEYER, 2003).

O que queremos dizer com isso é que, no seio das políticas públicas, em particular as de Educação, funcionam distribuições de poder que tendem a reificar normas regulatórias de gênero, as quais tomam forma nos corpos de homens e mulheres, mas também nos espaços físicos como os das escolas, na construção dos projetos institucionais e pedagógicos, nas relações entre profissionais e entre estes/as e os/as discentes, enfim, na construção de políticas educacionais e de práticas pedagógicas, adentrando os espaços cotidianos.

Antes de prosseguir, vale assinalar o que entendemos por gênero e por direitos humanos. Compreendemos gênero como construção que organiza o social (MEYER, 2003). Há processos de generificação que atravessam as relações sociais, as instituições e que ditam regras sobre as formas como devemos nos comportar, nos vestir, em que carreiras devemos atuar, com quais pessoas podemos nos relacionar sexual e afetivamente e, nessa direção, parece que o que é ou não permitido a cada indivíduo se define por atravessamentos de gênero e de sexualidade.

Direitos Humanos, por sua vez, dizem respeito àqueles direitos que visam proteger a dignidade humana. Uma vez que dignidade e cidadania encontram-se correlacionadas, entende-se que os direitos humanos devem ser garantidos pela lei, pelo Estado e pela sociedade. Por exemplo, se o direito à educação é fundamental para proteger a dignidade humana, ele deve ser assegurado pela lei, promovido e garantido por políticas (públicas) educacionais e outras práticas sociais diversas. Ou seja, ele se torna um direito de cidadania (garantido pela Constituição Federal e demais ordenamentos jurídicos que regulam a relação entre cidadãos e Estado, possibilitando o reconhecimento e a defesa desse direito humano) (AFONSO, 2011).

A concepção de quais seriam os direitos humanos necessários para garantir a dignidade humana transformou-se, ao longo da história, abrangendo hoje direitos civis, 
políticos, sociais, culturais, ecológicos, coletivos. Um dos motores dessas transformações relaciona-se justamente com os dilemas vividos entre igualdade e diversidade.

Assim, neste texto, buscamos refletir sobre a importância do trabalho com questões de gênero e sexualidade nas escolas como uma ferramenta pedagógica e política para exercício dos direitos humanos. Trata-se, pois, de um ensaio com reflexões teóricas e algumas pistas teórico-práticas oriundas de nossas inserções como docentes e técnicas que atuaram na formulação e implementação de políticas públicas recentes de âmbito nacional.

\section{ENTRE IGUALDADES E DIVERSIDADES, O PARADOXO DOS DIREITOS HUMANOS?}

Pode-se dizer que a luta pelos direitos humanos tem sido protagonizada pela busca da afirmação da igualdade entre todos os seres humanos. O primeiro artigo da Declaração Universal dos Direitos Humanos (1948) afirma que: “Todos os seres humanos nascem livres e iguais em dignidade e direitos e, dotados que são de razão e consciência, devem comportar-se fraternalmente uns com os outros". Inúmeras ações e políticas passam, assim, a se orientar de modo a garantir a igualdade entre as pessoas/cidadãs e a denunciar múltiplas desigualdades que se necessita suplantar para que os direitos humanos possam se efetivar.

Na medida em que o modelo de Estado-nação moderno, liberal e ocidental se afirmou sobre o pressuposto da homogeneidade cultural organizada em torno de valores universais (HALL, 2003; CANDAU, 2012), tem-se observado que muitas dessas desigualdades relacionam-se com questões de preconceitos face às diferenças (de raça/cor/etnia, gênero e sexualidade, região/território, faixa etária, religião, língua etc.), discriminação de rostos, corpos, modos de viver e de conviver que ousam perturbar a face hegemônica da cultura ocidental (branca, masculina, heterossexual, adulta) e a face homogênea dos direitos humanos. Em outros termos, o princípio da cidadania universal cego às diferenças, estabelece que todos os seres humanos são igualmente dignos de respeito, e com isso reforça a semelhança entre eles. Desse modo, extremas diferenças culturais de alguns grupos são postas entre parênteses, distorcendo-as e forçando-os a se conformar a uma cultura dominante, atribuindo-lhes uma cidadania de segunda classe, ou uma 'cidadania da sujeição' (CARVALHO, 2009). Dessa forma, entendemos que um dos desafios de nossos tempos para os direitos humanos parece se situar em habitar a relação entre desigualdades e diversidades (MOEHLECKE, 2009; CANDAU, 2012). 
A essa altura, cabe definir diversidade: apreendida em sua dimensão cultural, a diversidade é associada aos novos movimentos sociais, especialmente os de cunho identitário, articulando-se em torno da defesa das chamadas "políticas de diferença" (HALL, 2003). Como direito à diferença, a diversidade articula-se à exigência de reconhecimento na esfera pública e política de grupos sócio-culturais definidos como 'minoritários'.São os movimentos sociais, principalmente os de caráter identitário(movimento indígena, negro, quilombola, feminista, LGBT, dos povos do campo, das pessoas com deficiência, dos povos e comunidades tradicionais, sem terra, pessoas que vivem com HIV/aids, entre outros), que, a partir dos anos 1980, no Brasil, passam a indagar publicamente o funcionamento perverso da cultura ocidental capitalista de acirrar não só as desigualdades no plano econômico, mas também de tratar de forma desigual e inferiorizante coletivos sociais considerados diversos, grupos 'minoritários' com valores diferentes dos hegemônicos, veiculados como 'naturais'. Passa-se, assim, a enfatizar que os sujeitos de direitos são também diversos em raça, etnia, credo, gênero, sexualidade, idade, entre outros; aquilo que Bobbio (1992) intitula de "especificação de direitos". Enfatiza-se, também, que essa diversidade tem sido tratada de forma desigual e discriminatória ao longo dos séculos e que ainda não foi devidamente equacionada pelas políticas de Estado (FERRERI, 2011; CANDAU, 2012).

Nesse sentido, a problemática dos direitos humanos, muitas vezes entendidos como direitos exclusivamente individuais e fundamentalmente civis e políticos, se amplia. Cada vez mais se afirma a importância dos direitos coletivos, sociais,econômicos, culturais e ambientais. E, neste movimento, questões relativas à diversidade vêm adquirindo cada vez maior relevância.

Observa-se, pois, que os Direitos Humanos, entendidos como uma construção ocidental e moderna, precisaram - e precisam - de atualização conceitual/epistemológica e política, incorporando questões relacionadas à diversidade cultural.Em outros termos, o eixo dessa (re)conceitualização tem como eixo a articulação entre igualdade e diversidade. Dessa forma, outro desafio de nossos tempos para os direitos humanos parece se situar em habitar a relação entre igualdades e diversidades.

Acompanhando esse movimento intelectual/epistemológico e político, nos últimos anos, no Brasil e na América Latina, com avanços e limites, algumas dimensões de diversidade, pleiteadas historicamente pelos movimentos sociais e setores organizados da sociedade, começam a fazer parte da pauta da agenda das políticas públicas. O exemplo do Plano Nacional de Educação, trazido anteriormente, assim como o de um Projeto de Lei que 
tramita no Congresso Nacional ${ }^{3}$ e que pretende proibir professores/as de falarem sobre questões de gênero e sexualidade nas salas de aula ilustram alguns dos tensionamentos que temos vivido no campo da Educação no âmbito da abordagem de questões de gênero e sexualidade. Outro exemplo bastante é o da criação e alteração do Comitê de Gênero do Ministério da Educação (MEC). Criado pela Portaria No 916 de 09 de setembro deste ano de 2015, o Comitê de Gênero foi substituído, exatamente doze dias após sua publicação, em 21 de setembro de 2015, pelo Comitê de Combate às Discriminações, estabelecido pela Portaria $\mathrm{N}^{\mathrm{o}} 949^{4}$. O Comitê de Gênero tinha um papel bastante definido com responsabilidade de pensar estratégias voltadas às questões de gênero e, a partir de agora, com o novo nome, é possível que as ações específicas de gênero sejam substituídas por questões genéricas de enfrentamento às discriminações, ilustrando um cenário político bastante difícil no âmbito das questões de gênero e sexualidade.

Desse modo, temas relativos aos Direitos Humanos (e aqui chamamos especial atenção para aqueles vinculados às questões de gênero e sexualidade) transformam-se em temas de debate e de disputa na arena política. A discussão sobre a justiça social/reconhecimento da diferença passa a ocupar mais espaço na produção teórica, na análise e na implementação das políticas públicas, entre elas, as educacionais. Ou seja, a luta protagonizada pelos movimentos sociais contribui para a entrada do olhar afirmativo da diversidade na cena social, na cena estatal, na cena das políticas públicas, a escola, nos currículos.

Para finalizar essa parte do texto, uma ressalva deleuziana:

Os direitos do homem não nos obrigarão a abençoar as 'alegrias' do capitalismo liberal do qual eles participam ativamente. Não há Estado democrático que não esteja totalmente comprometido nesta fabricação da miséria humana. A vergonha é não termos nenhum meio seguro para preservar, e principalmente para alçar os devires, inclusive em nós mesmos. Como um grupo se transformará, como recairá na história, eis o que nos impõe um perpétuo ‘cuidado’ (DELEUZE, 1992, p. 213).

\footnotetext{
${ }^{3}$ Projeto de Lei 867/2015, de autoria do Deputado Federal Izalci Lucas, atualmente em discussão na Comissão de Educação da Câmara dos Deputados, propõe a inserção na Lei de Diretrizes e Bases (LDB) do Projeto Escola sem Partido que, entre outros itens, pretende a "neutralidade política, ideológica e religiosa do Estado" e em seu Art. $3^{\circ}$ indica que "São vedadas, em sala de aula, a prática de doutrinação política e ideológica bem como a veiculação de conteúdos ou a realização de atividades que possam estar em conflito com as convicções religiosas ou morais dos pais ou responsáveis pelos estudantes". Ou seja, é um projeto que atenta para a autonomia pedagógica dos/as professores/as e escolas no que diz respeito aos conteúdos que deverão ser abordados.

4 Informação disponível em: http://danielcara.blogosfera.uol.com.br/2015/09/22/governo-cede-a-pressao-esubstitui-comite-de-genero/. Acesso em: 23 de Set. 2015.
} 
Além da relação entre igualdades e diversidades, um dos grandes desafios de nossos tempos para os Direitos Humanos parece se situar entre igualdade e diferença. Ou seja, comportando, mas também se situando para além de classificações e identidades (mesmo culturais), pois não basta saber quem somos nós (o que é ser mulher, o que é ser homem, o que é ser hetero, o que é ser homo, por exemplo, já que estamos aqui enfocando igualdades e diferenças binárias de gênero e sexualidade) e nos filiar a um dos lados: igualdade ou diversidade. A esse respeito Suely Rolnik (1997, p. 21) faz uma ressalva importante:

[...] as ondas de reivindicação identitária das chamadas minorias sexuais, étnicas, religiosas, nacionais, raciais etc. Ser viciado em identidade nestas condições é considerado politicamente correto, pois se trataria de uma rebelião contra a globalização da identidade. Movimentos coletivos deste tipo são, sem dúvida, necessários para combater as injustiças de que são vítimas tais grupos; mas no plano da subjetividade trata-se aqui de um falso problema. O que se coloca para as subjetividades hoje não é a defesa de identidades locais contra identidades globais; é a própria referência identitária que deve ser combatida, não em nome da pulverização (o fascínio niilista pelo caos), mas para dar lugar aos processos de singularização, de criação existencial, movidos pelo vento dos acontecimentos. Recolocado o problema nestes termos, reivindicar identidades pode ter o sentido conservador de resistência a embarcar em tais processos.

Em outros termos, a diferença que queremos aqui afirmar é outra: aquela que se produz sem quaisquer parâmetros: aquela que acontece apela articulação entre diversos marcadores sociais (de gênero, de raça/cor/etnia, de faixa etária, de região, de religião etc.); aquela que acontece por hibridações e alianças em vez de filiações identitárias; aquela que não se nomina, escapa a normalizações; diferença-devir, que se tece articulada à vida, em toda sua potência de criação.

Diferença, de uma ideia justa à uma justa ideia (DELEUZE, 1992). Vitalizando o termo diferença, assim como temos tateado fazer com o termo gênero (VASCONCELOS; SEFFNER, 2015), apostando que um modo de exercício do direito à educação parece ser justamente o de construir uma zona de habitação entre igualdade e diferença, o convite é também o de, por meio de um olhar de gênero, testar o limite de suas fronteiras, (des)construindo territórios, desnaturalizando normas, (des)fazendo gêneros, operando passagens. 
GÊNERO, SEXUALIDADE E DIREITOS HUMANOS NA EDUCAÇÃO ESCOLAR: ENTRE IGUALDADES E DIVERSIDADES, A DIFERENÇA

\section{DESDOBRAMENTOS NO CONTEXTO ESCOLAR}

Saliente-se que a primeira geração dos Direitos Humanos diz respeito aos direitos civis e políticos, aos chamados direitos de liberdade, de proteção contra os excessos do Estado. A segunda geração engloba os direitos sociais, econômicos, culturais, por meio dos quais se reivindica proteção junto ao Estado. $\mathrm{O}$ acesso de qualidade à educação pública e gratuita faz parte dessa segunda geração. A Declaração Universal dos Direitos Humanos (1948) reconhece o direito à educação (pública e de qualidade). No Brasil, esse direito de cidadania está inscrito na Constituição Federal Brasileira de 1988, artigo 205: “a educação, direito de todos e dever do Estado e da família, será promovida e incentivada com a colaboração da sociedade, visando ao pleno desenvolvimento da pessoa, seu preparo para o exercício da cidadania e sua qualificação para o trabalho" (BRASIL, 1988), sendo explicitado e retomado, posteriormente, na Lei de Diretrizes e Bases da Educação Nacional - LDB (Lei 9.394/96) que indica, em seu Art. 2o, que a Educação, “dever da família e do Estado, inspirada nos princípios de liberdade e nos ideais de solidariedade humana, tem por finalidade o pleno desenvolvimento do educando, seu preparo para o exercício da cidadania e sua qualificação para o trabalho" (BRASIL, 1996).

Dessa forma, educa-se porque a educação (escolar) é um direito e, como tal, deve ser garantido de forma igualitária, equânime e justa. A expansão da escolarização e a afirmação da construção de uma educação escolar igual em condições e oportunidades para todos e todas, faz com que o direito à educação escolar se efetive na perspectiva da afirmação da igualdade, ampliando-se os anos de obrigatoriedade, universalizando-se a educação básica,harmonizando-se a base curricular comum e os modos de avaliação das escolas e dos processos de ensino-aprendizagem que ali acontecem.

Contudo, é preciso considerar que a obrigatoriedade da escolarização e a universalização do ensino, por exemplo, nunca se darão fora dos contextos sociais e culturais onde escola e comunidade escolar estão inseridas. Em relação à base curricular comum, estimulada desde LDB (e que inclusive se encontra, neste momento, em consulta pública via portal do Ministério da Educação), há que se pensar quais conteúdos são importantes de serem abordados por todas as escolas da educação básica e como todo processo de seleção, ao mesmo tempo em que escolhe deixa de fora e, assim, se configura em uma relação de poder (SILVA, 1999). Além disso, cabe perguntar: Por que construir uma base curricular focada em 
conteúdos? Não seria este um momento potente para repensar a escola e seu papel e construir um currículo que não fosse focado apenas em conteúdos? Nessa direção, corroboramos com Moreira e Silva (1998) quando indicam que, na composição de um currículo, a definição dos conhecimentos válidos e importantes sempre expressam os interesses dos grupos dominantes e, desse modo, reforçam as relações de poder existentes fazendo com que os grupos historicamente subjugados mantenham-se neste lugar.

Embora o direito à educação seja um direito de cidadania reconhecido e garantido por lei, apesar do avanço na universalização desse direito, no cotidiano escolar (inscrito num contexto perpassado por profundas desigualdades econômicas, sociais e culturais), enfrentamse inúmeras dificuldades em exercitá-lo.Nesse espaço, inúmeras desigualdades somam-se à herança de preconceitos e discriminações étnico/raciais, de gênero e sexualidade etc.

Desigualdades articuladas a diversidades atravessam o cotidiano das escolas: uma vez tendo conseguido entrar na escola, os/as estudantes se vêem às voltas com o desafio de sobreviver num cotidiano eivado de preconceitos que têm efeitos nefastos sobre seus desenvolvimentos, interferindo na qualidade das suas aprendizagens e, futuramente, na inclusão no mundo do trabalho, da política, da cultura. Na escola, tem-se reproduzido preconceitos étnico/raciais, de religião, de região/território, de gênero, de sexualidade etc. e é nas dobras da desconstrução desses preconceitos que apostamos. Assim, quando se afirma que o direito à educação deve ser igual para todos e todas, precisamos nos perguntar pelas desigualdades sociais, pelas necessidades diferenciadas, pelas identidades culturais e tantas outras questões que demonstram a diversidade social e humana. Disso decorre que o exercício de cidadania no contexto escolar envolve, concomitantemente, superar as desigualdades, abarcar/respeitaras diversidades, coletivas e singulares. Educação para todos/as e para cada grupo social/cultural, para cada sujeito individual e coletivo.

Mas, como afirmamos anteriormente, mais do que isso, quando levantamos a bandeira do direito à educação escolar temos a boa utopia (aquela que nos força o pensamento e que nos impulsiona a promover mudanças e que não nos deixa desacreditar e imobilizar), além da superação das desigualdades e respeito às diversidades, o que se quer é afirmar diferenças: educação para todos/as, para cada grupo social/cultural e para cada um/a de nós, com nossas singularidades e singularizações, estas últimas entendidas como "a diferença que resulta em nós e que desfaz o nós, abrindo-nos para outros modos de ser e de estar no mundo, bifurcando essa busca pelo homogêneo" (MEYER, FELIX, VASCONCELOS, 2013, p. 974) que ainda 
tende a pautar os resultados das lutas direitos humanos, mesmo que agora, em nome da diversidade.

\section{DIREITOS DE TODOS/AS, DIREITO DE CADA GRUPO, DIREITO DE CADA UM/A}

A questão da diversidade, especialmente na última década, tem sido cada vez mais presente no debate e no contexto escolar brasileiro. Basta observar a inserção curricular de questões indígenas, afro-brasileiras, da diversidade sexual e das deficiências, o aparecimento da discussão sobre educação especial, tudo isso regulado por leis e normas, a exemplo dos já mencionados PNE 2014-2024 e LDB. Podemos aqui também assinalar a elaboração de materiais pedagógicos para o enfrentamento da homofobia, do sexismo, do racismo no ambiente escolar e falar dos debates e embates políticos sobre as especificidades da educação quilombola, educação no campo etc.

A pressão histórica dos movimentos sociais somada a alguns setores do Estado brasileiro trouxe mudanças expressivas no que se refere ao pautar e lidar com a diversidade no contexto das políticas públicas, desencadeando, inclusive, a implementação de políticas de ações afirmativas. Contudo, três limites ainda persistem e são importantes de considerar aqui: 1)a questão de que a maioria dessas ações ainda se restringe às políticas de governo, faltando um enraizamento como políticas de Estado; 2) o fato de que as ações afirmativas tendem a funcionar como ações fragmentadas e direcionadas a grupos específicos, prevalecendo ações específicas direcionadas a segmentos populacionais: às mulheres, aos deficientes, aos/às indígenas, aos/às negros/as etc. Ou seja, não se conseguiu, até o momento, alcançar o objetivo de transversalizar a perspectiva da diversidade e desenvolver programas e projetos voltados para os públicos e temas da diversidade de modo articulado; 3) políticas de igualdade e de reconhecimento da diversidade referidas à educação escolar parecem, algumas vezes, estar em contraposição (MOEHLECKE, 2009).

Tais limites (se quisermos transmutá-los em desafios) relacionam-se com a necessidade de enfrentarmos, inclusive no campo das políticas públicas, dois problemas: 1) o convívio entre diversidades, pois as particularidades culturais são inúmeras, híbridas, misturadas; 2) a questão ética da afirmação da diferença, da infinita capacidade de mestiçagem das vidas humanas, da força humana de inundar a vida e rebentar suas represas. Conforme afirma Ferreri (2011), as questões em Direitos Humanos se tornam densas: não 
basta afirmar o direito das mulheres se não se reconhece a particularidade da mulher negra; não basta afirmar o direito do homem negro, se não se reconhece as pautas do movimento gay. Os direitos humanos são capazes de cooperar para a coabitação das diversidades? Os direitos humanos são capazes de acompanhar a hibridação e nomadismo das vidas humanas que se tecem entre múltiplas diversidades e se fazem únicas? Os direitos humanos são capazes de se despir de suas vestes homogêneas e transcendentais e olhar o nu e o cru da vida humana? Esses são alguns dos muitos desafios e questionamentos que ainda precisam ser enfrentados e pensados no percurso de uma história das políticas públicas brasileiras ainda por vir, sobretudo, as educacionais.

Nesse ponto, cabe lembrar que o caráter público dos projetos e programas que dão corpo a uma política (pública) se faz quando expressam interesses coletivos e não apenas estatais. Dessa forma, cresce a aposta de que não basta construir um arcabouço jurídico cada vez mais amplo em relação aos direitos humanos, sem se construir uma cultura de direitos humanos (AFONSO, 2011; FERRERI, 2011). Nesses tempos em que alunos/as e professoras/es se perguntam o que estão fazendo ali, nos parece que a escola tem uma função fundamental nessa construção: educar para a cidadania (não a da sujeição), articulando afirmação das igualdades e das diversidades e o direito a diferir, enfrentando os desafios relacionados a tal afirmação.

Em tempos de retrocessos históricos em torno dos direitos humanos, especificamente daqueles voltados às questões de gênero e sexualidade, nos parece importante resistir para que sejam criadas condições de (re)existir; criar dobras; abrir novas fendas e outros caminhos.Em outros termos, apostamos na potencialidade de se fazer (micro)política no ambiente educacional, exercitando coletivamente,por entre polifonia de vozes diversas, o direito à educação (e não só a escolar) como um direito de todos/as, de cada grupo e de cada um/a (CANDAU, 2012).

Em outras palavras, de nosso ponto de vista, formar pessoas a partir dos ideais da solidariedade humana e que sejam capazes de exercer cidadania, no sentido que aqui estamos apostando, requer práticas formativas que, ao mesmo tempo em que se embasem nos preceitos dos Direitos Humanos, os alarguem. Almeja-se, pois, não somente valorização e respeito às diversidades, mas às singularidades e singularizações. Requerem-se movimentos de (des)aprendizagem de toda uma história que nos foi inculcada a condicionar limites e fronteiras para a humanidade, uma trajetória acoplada a normas regulatórias de condutas, como por exemplo, as normas regulatórias de gênero. Exige-se, enfim, uma transvaloração do 
humano, aos moldes nietzschianos (PAULON, 2006). Reconhecemos que, se por um lado, essa não é uma tarefa simples, pois formar a partir desses norteadores é algo cada vez mais difícil nesses nossos tempos de (auto)vigilância e controle. Por outro, esse é o grande desafio colocado para práticas formativas que apostam na afirmação da vida, no alargamento de territórios existenciais: formar bem ali entre igualdades, diversidades e diferença.

\title{
GÉNERO, SEXUALIDAD Y DERECHOS HUMANOS EN LA EDUCACIÓN ESCOLAR: ENTRE IGUALDADES Y DIVERSIDADES
}

\section{Resumen}

Ese texto objetiva discutir tensionamientos políticos y pedagógicos envueltos enlas implicaciones del derecho a la educación como um derecho a La igualdad y a la diferencia; y pensar El desafío de crearse una zona de habitación entre igualdad y diferencia em el campo de las políticas públicas educacionales, tomando el género como un operador de análisis. El movimiento metódico es el de tentar imprimir un mirar de discusión, posicionándonos contra eles vaciamiento de sentidos por lanaturalización de nocion estan utilizadas en la lucha política como la de derechos y la de humanidad. Enesos tiempos en que alumnos/as y profesoras/es se preguntan qué estánhaciendo allí, nos parece que la escuela tiene una función fundamental de educar para La cuidadania. Apostamos em la potencialidad de hacer (micro)política enel ambiente educacional, ejercitando colectivamente, entre polifonía de diversas voces, el derecho a la educación (y no solo al escolar) como un derecho de todos/as, de cada grupo y de cada un/a.

Palabras-claves: Educación; Escuela; Derechos Humanos; Género; Sexualidad

\section{GENDER, SEXUALITY AND HUMAN RIGHTS IN SCHOOL EDUCATION: BETWEEN EQUALITIES AND DIVERSITIES}

\begin{abstract}
The current study aims to discuss the political and pedagogical tensions involved in unfolding the right to education as a right to equality and to difference. It also aims to reflect about the challenge of sheltering equality and difference in the educational public policy field, by taking
\end{abstract}


VASCONCELOS, M. F. F.; FÉLIX, J.

gender as analytical operator. The methodical movement consists in questioning and positioning ourselves against the emptying of meaning by the naturalization of concepts such as rights and humanity, which are often used in the political struggle. In times when students/teachers wonder about what they are doing, it seems that the school plays the fundamental role of educating for citizenship. We believe in the power of making (micro) policies within the educational environment, by collectively exercising, through a polyphony of different voices, the right to education (not just school education) as the right of all, of each group and of each individual.

Keywords: Education; School; Human Rights; Gender; Sexuality

\section{REFERÊNCIAS:}

AFONSO, Lúcia. A importância da escola para a construção de uma cultura d e promoção e defesa dos Direitos Humanos. In: DESLANDES, Keila; LOURENÇO, Érika (orgs.). Por uma cultura dos direitos humanos na escola: princípios, meios e fins. Belo Horizonte: Fino Traço, 2011. p. 7-12.

BOBBIO, Norberto. A era dos direitos. 11. ed. Rio de Janeiro: Campus, 1992.

BRASIL. Lei de Diretrizes e Bases da Educação Nacional, Lei nº 9.394, de 20 de dezembro de 1996. Disponível em: http://portal.mec.gov.br/arquivos/pdf/ldb.pdf. Acesso em: 23 deSet. 2015.

Constituição da República Federativa do Brasil de 1988. Disponível em: http://www.planalto.gov.br/ccivil_03/constituicao/ConstituicaoCompilado.htm. Acesso em: 23 de Set. 2015.

CANDAU, Vera. Educação em direitos humanos: desafios atuais. In: SILVEIRA, Rosa Maria (org.). Educação em Direitos Humanos: fundamentos teórico-metodológicos. João Pessoa: Editora Universitária, 2012. p. 399-412.

CARVALHO, Sérgio Resende. Reflexões sobre o tema da cidadania e a produção de subjetividade no SUS. In: CARVALHO, Sergio Resende; BARROS, Maria Elizabeth e FERIGATO, Sabrina (Org.). Conexões: saúde coletiva e políticas da subjetividade. São Paulo: Aderaldo \&Rothschild, 2009, pp. 23-41.

COIMBRA, Cecília. L. Operação Rio: o mito das classes perigosas.Rio de Janeiro: Intertexto, 2001.

; NASCIMENTO, M. Lívia. A invenção do humano como modo de assujeitamento. In: MENDONÇA FILHO, M.; NOBRE, M. T. Política e afetividade: narrativas e trajetórias e pesquisa. Salvador: EDUFBA; São Cristóvão, SE: EDUF, 2009. p. 31-42. 
GÊNERO, SEXUALIDADE E DIREITOS HUMANOS NA EDUCAÇÃO ESCOLAR: ENTRE IGUALDADES E DIVERSIDADES, A DIFERENÇA

DELEUZE, Gilles. Conversações (1972-1990). São Paulo: Editora 34, 1992. (Coleção Trans).

EIRADO; A.; PASSOS, E.. A noção de autonomia e a dimensão do virtual.2004. Psicologia em Estudo, v. 9,Maringá, n. 1. 2004. pp.77-85.

FOUCAULT, Michel. História da sexualidade I: a vontade de saber. Rio de Janeiro: Edições Graal, 2001.

. Nascimento da biopolítica. São Paulo: Martins Fontes, 2008.

LARROSA, J.; SKLIAR, C. Babilônios somos. A modo de apresentação. In:

(org.). Habitantes de Babel: políticas e poéticas da diferença. Belo Horizonte: Autêntica Editora, 2001. p. 7-29.

FERRERI, Marcelo. A era dos direitos entre conflitos e diversidades políticas.In:

DESLANDES, Keila; LOURENÇO, Érika (orgs.). Por uma cultura dos direitos humanos na escola: princípios, meios e fins. Belo Horizonte: Fino Traço, 2011. p. 13-36.

HALL, Stuart. A identidade cultural na pós-modernidade. 7. ed. Rio de Janeiro: DP\&Z, 2003.

MEYER, Dagmar E. E. Gênero e educação: teoria e política. In: LOURO, Guacira Lopes; FELIPE, Jane; GOELLNER, Silvana Vilodre. Corpo, gênero e sexualidade: um debate contemporâneo na educação. Petrópolis: Vozes, 2003. p. 9-27.

; FÉLIX, J.; VASCONCELOS, M. F. F.. Por uma educação que se movimente como maré e inunde os cotidianos de serviços de saúde. Interface - Comunicação, Saúde, Educação, vol. 17, núm. 47, out-dez, 2013, pp. 859-871.

MOREIRA, A. F. B.; SILVA, T. T. Currículo, Cultura e Sociedade. São Paulo: Cortez, 1998.

ORGANIZAÇÃO DAS NAÇÕES UNIDAS. Declaração Universal dos Direitos Humanos. Disponível em: http://www.dhnet.org.br/direitos/deconu/textos/integra.htm. Acesso em: 23 de Set. 2015.

MOEHLECKE, Sabrina. As políticas de diversidade na educação no governo Lula. Cadernos de Pesquisa (Fundação Carlos Chagas. Impresso), v. 39, p. 461-487, 2009.

PASSETTI, Edson. Anarquismos e sociedade de controle. São Paulo: Cortez Editora, 2003.

PAULON, Simone. A desinstitucionalização como transvaloração. Apontamentos para uma terapêutica ao niilismo. Athenea, n. 10, p. 121-136, 2006.

PELBART, Peter. Subjetividade e pós-modernismo. In: ARÁN, M. (org.). Soberanias. Rio de Janeiro: Contra Capa, 2003. p. 31-40.

ROLNIK, S. Toxicômanos de identidade: subjetividade em tempo de globalização. In: LINS, D. (org.). Cultura e subjetividade: saberes nômades. Campinas: Papirus, 1997. p. 19-24. 
Tristes gêneros. In: D. LINS (org.). A dominação masculina revisitada. Campinas: Papirus, 1998. p. 63-68.

SANTOS, Boaventura de Souza. Introdução: para ampliar o cânone do reconhecimento, da diferença e da igualdade. In: . Reconhecer para libertar: os caminhos do cosmopolitanismo multicultural. Rio de Janeiro: Civilização Brasileira, 2003.

SILVA, Tomaz Tadeu da. Documentos de identidade: uma introdução às teorias do discurso. Belo Horizonte: Autêntica, 1999.

VASCONCELOS, M.; SEFFNER, F. A pedagogia das políticas públicas de saúde: norma e fricções de gênero na feitura de corpos. Cadernos Pagu (44), janeiro-junho, Campinas: 2015. p.261-297.

Data de recebimento: 03/02/2016

Data de aceite: 01/03/2016 